\title{
Pro-Environmental Consumer Behavior: A Critical Review of Literature
}

\author{
Owino Odhiambo Joseph ${ }^{1}$ \\ ${ }^{1}$ Department of Business Administration, University of Nairobi, Kenya \\ Correspondence: Owino Joseph Odhiambo, Department of Business Administration, University of Nairobi, P.O. \\ Box 30197, 00100 Nairobi, Kenya. E-mail: jowino@uonbi.ac.ke
}

Received: November 5, 2019

Accepted: December 1, 2019

Online Published: December 12, 2019

doi:10.5539/ijbm.v15n1p1

URL: https://doi.org/10.5539/ijbm.v15n1p1

\begin{abstract}
The damage to the environment caused by commercial activities and consumption behaviours has become a reason for concern in recent times. Sustainable consumption and drivers behind it was the main objective of the study. The study is a critical review of literature on pro-environmental behaviours with focus on theory, behavioural drivers and inhibitors. The review covered conceptual and empirical papers selected from peer reviewed articles with high citation index. Behaviour change theories including theory of reasoned action, theory of planned behaviour, norm activation theory and goal framing theory were reviewed. In light of theory, attitude, behavioural intention and perceived consequences are the major variables that cause pro-environmental behaviour. Nevertheless, norm activation theory fails to explain behaviour where people are in denial of responsibility for the consequences of their consumption. The study established that pro-environmental behaviour is caused by both intrinsic and extrinsic factors. Intrinsic factors include environmental awareness and knowledge, attitude, consumer age, education, and concern for the environment. Extrinsic factors including income, social network and culture bridge the gap between attitude and pro-environmental behaviour. Perceived high price and lack of trust for green products were the major barriers to sustainable consumption behaviours. The study concludes that interaction between consumer attitude and favourable contextual factors lead to pro-environmental behaviours.
\end{abstract}

Keywords: pro-environmental, green-product, sustainable, attitude, behaviour

\section{Introduction}

Pro-environmental consumer behaviour also known as ecological behaviour/green purchasing/sustainable consumer behaviour has been associated with broader societal ethical considerations and individual consumer values, attitudes and situational factors. Pro-environmental consumer behaviour is both an intrinsic and extrinsic deliberate responsive actions by individuals to protect the environment (Corral-Verdugo, 2001; Kollmuss \& Agyeman, 2002), reduce negative consequences on the ecosystem and ensure sustainability of future generations. Papaoikonomou et al. (2011) consider pro-environmental consumer behaviour as a type of ethical disposition premised on environmental conservation that secures the future through sustainable production and consumption. Similarly, Castaneda et al. (2015) relate pro-environmental consumer behaviour with actions by individuals and consumer groups that are not dangerous to the environment. Environmental protection is central to the definition of pro-environmental consumer behaviour as expressed by Joshi and Rahman (2015) who declare that eco-behaviour is an ethically driven decision that factors sustainability of the eco-system prior to purchase, during and after consumption experience.

The issue of environmental protection and sustainable use of resources are closely associated with consumer behaviour. Environmental problems experienced by society are linked to consumer lifestyles. Consumers who behave in a more environmentally friendly way change the patterns through which they acquire, use, and dispose of products (Pieters, 1991). Pro-environmental consumers depict behaviours such as recycling, choosing eco-friendly packaging, minimizing wastes, ethical disposal of non biodegradable materials, and environmental consciousness in buying decision ( $\mathrm{Lu}$, Chang \& Chang, 2015). Insight into consumption patterns and in the factors influencing them is required to identify environmentally friendly alternatives and the necessary approaches to stimulate those alternatives. To date, research on factors that drive or impede pro-environmental consumer behaviour is inconclusive, and results inconsistent with predictions of relevant theories have been 
reported (Olney \& Bryce, 1991).

Previous studies on green marketing have attempted to profile pro-environmental consumer behaviour using variables that include socio-demographic characteristics (Diamantopoulos et al., 2003; Straughan \& Roberts, 1999), psychographics (Do Paco \& Raposo, 2008; Gilg et al., 2005) and contextual variables (Tremblay \& Dunlap, 1978). Socio-demographics are concerned with age, gender, education, income and social networks (Buttel \& Taylor, 1992; Straughhan \& Roberts, 1999). The psychographic division include environmental knowledge (Mostafa, 2007), environmental attitude (Kim, 2011), moral concern (Dean et al., 2008), ethical motives and judgement (Honkanen et al., 2006; Chan et al., 2008), and religiosity (Bhuian \& Sharma, 2017). Consumer behaviour profiles have been used by previous studies to explain pro-environmental inclination of individuals and consumer groups in the society. The major categories of previous studies are, on the one hand conceptual studies using social behaviour theories to predict pro-environmental behaviour. On the other hand, empirical studies, over the last two decades have attempted to test predictions of behaviour change theories using observations made from different cultures across the world. The main guiding theories from extant literature include: social exchange theory, theory of reasoned action and the theory of planned behaviour. Other theoretical frameworks that explain pro-environmental consumer behaviour comprise goal framing theory, norm activation theory, and the Hunt-Vitell model of ethical behaviour.

Consistent with majority of behaviour change theories, empirical studies demonstrate that pro-environmental consumer behaviour is influenced by a complex interplay of factors within the consumer (intrinsic) and forces out of the consumer's control (extrinsic). Intrinsic factors include consumer's psychological makeup, education level, values, and attitudes. Comparatively, extrinsic factors entail consumer's disposable income, time available, amount of effort involved and social relations (Spangenberg \& Lorek, 2002). While intrinsic factors shape consumer preferences, extrinsic factors determine the degree to which preferences or aspirations can be realized. Whereas several theories argue that intrinsic factors explain pro-environmental behaviour, empirical evidence from some studies point out the gaps between theory and actual behaviour, and in contrast suggest that intrinsic factors do not necessarily lead to actual performance of green consumption behaviours (Sharma \& Bansal, 2013). Therefore, extrinsic factors have been used to explain the gap between intrinsic factors such as attitude and actual consumer behaviour. Nevertheless, possibilities of mediating factors between intrinsic factors and actual consumer behaviour cannot be ruled out. Given that consumer behaviour is shaped by values and attitudes, research suggests that it is possible to tilt people's attitudes towards pro-environmental consumption through marketing mix tools such as awareness creation, green-product design, eco-distribution and incentive laden pricing (Curran \& Sherbinin, 2004). Witkowski (2005) argues that although marketing recognizes that purchasing decisions are influenced by all sorts of impulses, the greatest ideal remains that of a rational consumer. Thus, awareness creation increases consumer knowledge on environmental issues with the potential for making informed choices.

The paper presents a review of key issues relating to pro-environmental consumer behaviour. The paper adopts critical review to identify theories and key trends in literature. The review commenced by identifying relevant journal databases in business and environmental issues, followed by searching for peer reviewed journals. Selection of the articles for review from each journal was guided by relevance to pro-environmental issues and citation index. The review covered both conceptual and empirical papers published in peer reviewed journals. While conceptual papers provide theoretical frameworks that predict pro-environmental behaviour, empirical studies depict varied behaviour of consumers from different parts of the world in the context of green marketing. The review focuses on studies that describe, explain or predict pro-environmental consumer behaviour in terms of behavioural drivers and inhibitors. Selection of papers for review was done by search of keywords in the title and abstracts of peer reviewed journal articles. Some of the keywords used in combinations include 'pro-environmental behaviour', 'environmentally conscious consumers', 'sustainable consumption', 'green purchasing', and 'eco-behaviour'. In the following sections of the paper, a review of theoretical frameworks that explain pro-environmental consumer behaviour is presented. Next, the paper presents a critical review of literature on drivers and barriers to pro-environmental consumer behaviour.

\section{Theoretical Frameworks}

Pro-environmental consumer behaviour gained academic traction in the twentieth Century after explorative works in the 1990s. An array of behaviour change theories including the theory of reasoned action (Fishbein \& Ajzen, 1975), norm activation theory (Schwartz, 1977), theory of planned behaviour (Ajzen, 1991) and the goal framing theory (Lindenberg \& Trijp, 2013) are reviewed. The theory of reasoned action (TRA) argues that human behaviour is directly influenced by behavioural intention. Intention in turn is formed by attitude (intrinsic factor) and subjective norm (extrinsic factor). Based on the theory, attitude is the subjective evaluation of 
consequences of behaviour and their associated perceived values. On the other hand, subjective norm is defined as an individual's opinion of the behaviour expected from them by significant others within their social network and the level of motivation by the individual to comply with this expectation (Trafimow, 2009). Subjective norm is determined by normative beliefs. Intention in the pro-environmental behaviour context is the outcome associated with willingness to modify behaviour such that it causes less harm to the environment (Ramayah, Lee \& Mohamad, 2010). Clark et al. (2013) explain that behavioural intentions are formed by attitude and beliefs individual consumers hold regarding the environment. Mancha and Yoder (2015) argue that behavioural intentions are strongly influenced by social pressure to the extent that perceived peer expectation of ecological conscious behaviour would influence a person to be pro-environmental. As can be seen from the above account, behavioural intentions are formed by consumer intrinsic and extrinsic factors.

TRA assumes unequal influence of attitude and subjective norm in the formation of behavioural intention. The theory holds that, depending on the decision making situation, either attitude or subjective norm plays a dominant role in creating intentions that lead to consumer behaviour. Despite the assumptions of TRA, researchers have questioned the predictive power of attitude on consumer behaviour. The link between attitude and behaviour has not been supported by majority of empirical studies in the context of pro-environmental consumer behaviour (Joshi \& Rahman, 2015). Although environmental attitude is associated with pro-environmental consumer behaviour, evidence linking attitude with specific environmental behaviour is scant (Oom Do Valle et al., 2005). Whereas TRA claims that attitude is a cognitive variable, other researchers argue that attitude has both cognitive and affective components. Therefore, the theory suffers from definition deficiencies and circular arguments that render it unfalsifiable. Moreover, the influence of situational factors on behavioural intentions remains contentious (Mainieri et al., 1997).

To address the limitations of TRA, AJzen (1988) proposed the theory of planned behaviour (TPB) which explains behaviour over which consumers lack volitional control. TPB, an extension of TRA argues that behavioural intention is created by attitude and subjective norm. Unlike its predecessor, TPB assumes that consumer behaviour is not only determined by intention, but also directly determined by perceived behavioural control (Ajzen, 1991). Perceived behavioural control is defined as the amount of control people think they have over their own behaviour. In essence, perceived behavioural control infers a person's perception of contextual factors that influence performance of the behaviour. Access to and ownership of resources such as skills, assets and time portray the level of control consumers have over their behaviour. The theory (TPB) assumes that performance of behaviour is explained by attitude to the extent that the consumer has control over their behaviour. Further, TPB avers that performance of behaviour would increase with the magnitude of perceived behavioural control to the extent of the individual's motivation (Ajzen, 1991).

Empirical evidence in support of the theory's predictions is found in a study by Wang et al. (2014) who demonstrated that perceived behavioural control has a significant and positive impact on behavioural intentions and actual pro-environmental purchase behaviour. TPB predicts that performance of behaviour is a relative balance between intention and perceived behavioural control that vary depending on the situation and across different behaviours. In the context of pro-environmental behaviour, Reser and Bentrupperbaumer (2005) explain that environmental values play significant role by influencing personal norms that lead to behaviour. Studies (Eze \& Ndubisi, 2013; Wang et al., 2014) provide empirical evidence positively linking consumer ethical values with pro-environmental behaviours. Ajzen (1991) argues that alignment of individual's personal interest with behaviour propels pro-environmental behaviour compliance. Nevertheless, values alone in exception of situational factors may not be good predictors of pro-environmental consumer behaviour. Although TPB proposes antecedents to behavioural intentions, it fails to explain how consumers make decisions related to purchase situations (Carrington et al., 2010).

Alternative explanation of pro-environmental consumer behaviour is found in theories that consider the role of contextual factors in not only shaping behaviour, but also influencing attitude and behaviour relationship. Schwart's norm activation theory presents three pro-environmental antecedents comprising awareness of consequences, attribution of responsibility, and personal norms (Sawitri et al., 2015). The theory predicts that awareness of negative consequences of behaviour and ascription of personal responsibility trigger personal norms that control an individual's anticipatory actions against the destructive outcomes (Gifford \& Nilsson, 2014). Put into perspective, awareness of negative consequences of the use of energy intensive appliances to the environment for example, and ascription of personal responsibility to slow down global warming would motivate an individual to use energy efficient devices. Secondly, awareness of detrimental consequences of pollution by non-biodegradable packaging and attribution of personal responsibility for reducing environmental degradation would trigger personal norms that encourage pro-environmental consumer behaviours such as recycling, buying 
green products and responsible disposal of wastes. The theory suggests that personal norms increase with the intensity of awareness of negative consequences and acceptance of responsibility for outcomes. Although the theory presents plausible predictions, it fails to explain failure to perform behaviour on the basis of contextual circumstances. Awareness of negative consequences and ascription of personal responsibility may indeed lead to development of personal norms, but the mere presence of norms without supporting contextual factors may not automatically trigger anticipatory actions against harmful outcomes. Absence of supporting contextual factors such as relevant government policy, income, and green products may actually compel a person to perform reverse behaviour, though with potential individual regret of the decision.

The goal framing theory sheds light on contextual factors that influence pro-environmental consumer behaviour. It is based on the evidence that human cognitive processes and behaviour are modularly organized (Lindenberg \& Steg, 2007). Flexible modularity is accomplished by the strength of the goals to trigger cognitive and emotional processes. The theory argues that multiple motivations are accountable for human behaviour (Steg \& Vlek, 2009). Goal framing theory holds that goals govern information processing by individuals and the actions taken thereof. In the lens of the theory, thinking about behaviour is influenced by activation of a goal, selective information processing, evoked set of behavioural options and the likely actions to be taken by the individual. Three general goal-frames comprise hedonic goal-frame, a gain goal-frame, and the normative goal-frame. The hedonic goal-frame is concerned with the desire for immediate pleasant feeling. Gain goal-frame addresses itself to safeguarding and improving one's pool of resources. Normative goal-frame relates to taking appropriate action for the group in a given situation. All the three goal-frames are strongly influential in predicting behaviour. However, the strength of the influence of each goal on cognitive and emotional processes are unequal at any given time and depends on internal and external cues triggered by the specific goal giving it momentarily stronger power than the other two.

The theory assumes that in the absence of hedonic and gain goals; normative goal-frame is likely activated by social norms held by people (Lindenberg, 2009). Social norms are the shared evaluations and priorities that are unofficially enforced through sanctions (Horne, 2001). Goal framing theory argues that strong social support is necessary to sustain norm guided behaviour due to its unstable nature. Norm guided behaviour is sensitive and can be destroyed by deviations from social values by few people (Lindenberg \& Steg, 2013). The theory argues that deviation from the norm is contagious (Gino \& Pierce, 2009) and for an average person in the society, defiance implies approval of the infractions. Violation of a single rule weakens the normative goal triggering violation of other rules.

Goal framing theory assumes that multiple goals are activated at any one given time, and that compatibility of an individual's background with goal frame strengthens the latter. However, the theory is cognisant of the role played by contextual factors in addition to motivation in determining consumer behaviour. Therefore, the theory suggests that contextual factors may either impede or facilitate pro-environmental consumer behaviour (Thogersen, 2005). Furthermore, contextual factors may influence motivation either positively or negatively. Santos (2008) advocates for the theory's predictions by explaining that, affordability and availability of green products for example, may encourage pro-environmental consumption behaviours. In cases where contextual constraints are severe, pro-environmental consumer behaviour can be perceived as costly and the motivation by individual may be weakened to the extent that it has little influence on the pro-environmental consumer behaviour. Therefore, normative goal is considered very exposed to pre-existing stronger forces of hedonic and gain goals and can deteriorate under situational factors priming the two goals (Lindenberg \& Steg, 2013). Norms that are relevant to pro-environmental consumer behaviour are activated by ecological values. Hence, the stability of pro-environmental consumer behaviour depends on stable normative goal-frame that in turn requires broader contextual support. So far, the theories reviewed predict pro-environmental behaviour based on consumers intrinsic and extrinsic factors. In the remainder sections of the paper, drivers and barriers to pro-environmental consumer behaviour are discussed.

\section{Drivers of Pro-Environmental Consumer Behaviour}

Pro-environmental consumer behaviour has been a subject of investigation in recent times as consequences of consumer behaviour on the environment attract attention of policy makers and researchers. Consumption behaviour is the focal point of analysis since it has both positive and negative consequences on the biosphere (Narula \& Desore, 2016). Available literature suggests that the aspects of human behaviour related to the environment have been pursued adequately by empirical studies particularly in the developed countries. Narula and Desore (2016) observed that people in developed countries were more aware about pro-environmental issues as compared to communities living in developing countries. Pro-environmental variations on the basis of industrialization and race may be attributed to the negative consequences of industrialization and consumer 
alertness to dangers posed by industries to the environment.

As a country experiences economic growth, there are possibilities that without ethical culture, industries may dispose wastes in ways that pollute the environment and compromise the quality of life for society. In addition, the economic logic of profitability in competitive industries may force firms to pursue cost cutting strategies, some of which may include overuse of a resource, use of production processes that have negative consequences to the environment, and production of products whose consumption pose danger to the ecosystem. According to Davis (1992) the magnitude of the green marketing movement is indeed enormous. Intrinsic factors encompassing awareness, consumer attitude, cognitive processes and decision making have been linked to pro-environmental behaviour.

Consumer awareness and knowledge are the basic requirements for behaviour change. Consumers who are aware and knowledgeable about the consequences of their own consumption related behaviour on the environment are more likely to modify or change their behaviour in ways that reduce negative impact on the environment. Laroche et al. (2001) portend that consumer awareness about environmental issues increases the likelihood of green product consideration in a purchase situation. Access to environmental information about products increases market acceptance of green products even when they attract higher price relative to ordinary products (Michaud \& Llerena, 2011). While awareness raises concern for the environment, consumer knowledge builds a sense of responsibility for one's own behaviour to the extent that more knowledgeable consumers tend to be altruistic in their behaviour. Interestingly, studies have reported that concern for the environment increases the desire among people to look for information that increases both their awareness and ecological knowledge (Joshi \& Rahman, 2015). Environmental knowledge has been found to have positive influence on pro-environmental intentions and purchase decisions (Eze et al., 2013). On the matter of specific role of knowledge, Joshi and Rahman (2015) clarify that environmental knowledge moderates the relationship between attitude and ecological consumer behaviour.

Studies have linked awareness and concern about the environment with pro-environmental consumer behaviour. Malik et al. (2019) found out that consumer's awareness of ecological products was positively associated with pro-environmental intentions and concern. However, the authors clarify that awareness influences pro-environmental behaviour through ecological concern on condition that the latter is strong enough to predict green purchase behaviour. Intention is the unconditional state of mind wherein pro-environmental choices are made (Farrukh et al., 2018). Using a case study analysis of household waste management in the United Kingdom, Barr (2007) established that concern for the environment predicted pro-environmental consumer behaviour than intention. Nevertheless, concern for the environment potentially creates behavioural intentions that ultimately predict actual consumer behaviour. Therefore, the results obtained by Barr (2007) require confirmatory tests before arriving at conclusions about concern and behaviour connection. Separately, Wang et al. (2014) reported that ecological concerns and responsibility had a positive and direct impact on environmental knowledge, purchase intention and actual purchase behaviour. Furthermore, using empirical evidence, Muralidharan and Xue (2016) support the direct impact of environmental concern on consumer buying behaviour. In contrast, studies negating the relationship between awareness and pro-environmental consumer behaviour are beginning to emerge. Mohr, Webb and Harris (2001) argue that environmental issues play secondary role in consumer's purchase behaviour in several societies. Bray, Johns and Killburn (2011) observed that despite increased awareness about pro-environmental issues, market share for green products have remained below $4 \%$ globally. Sharma and Foropon (2019) established that in majority of societies, rational purchase decisions override affective environmental attitude. Essentially, people may be concerned about the environment, but fail to buy products with less harm to the environment perhaps due to situational factors that influence the decision making process and behavioural outcomes.

It is important to realize that awareness about environmental issues is the foundation of attitude formation. Whereas attitude determines the level of concern people have for the environment, pre-existing concerns reinforces both the cognitive and affective components of attitude. Hence, environmentally conscious consumers who have concern for posterity are most likely to display positive attitude towards green consumerism. This line of thinking is supported by Young et al. (2010) who found that consumer guilt have a significant influence on pro-environmental behaviour. Attitude is linked to personal beliefs (Zhao et al., 2014), such that one's concern for the environment is based on the individual's attitude. Castaneda et al. (2015) argue that consumers with pro-environmental attitude are more likely to care about environmental issues that confront society. However, attitude itself is a product of society as societal context reinforces positive and negative feelings about the environment. Attitudes are made up of multiple beliefs concerning specific objects or acts (Follows \& Jobber, 2000). According to Tan (2011), pro-environmental attitude is the concern demonstrated by the consumer 
towards good condition and sustainability of the environment. Joshi and Rahman (2015) consider environmental attitude as the psychological tendency of either positive or negative evaluations of the environment. Muralidharan and Xue (2016) suggest that environmental attitudes are developed through socialization process wherein people acquire relevant knowledge, skills and experiences from social agents.

Social structural variables including consumer demographics, social class and religion create the platform where attitudes develop. Earlier research suggests age and education are the most important demographic predictors of pro-environmental behaviour (Buttel \& Taylor, 1992). Pertaining to age, Straughan and Roberts (1999) observe that younger people are more concerned about the environment, but their actual pro-environmental behaviour depends on conviction about society's effectiveness in fighting environmental problems. Carrete et al. (2012) report that younger people in Mexico were found to actively reduce wastes, reuse products and had recycling tendencies as compared to adults. In a rather surprising turn, their study suggests that children had higher environmental knowledge than their parents. Considering that knowledge is cumulative over time, one would imagine that age plays a significant role in the acquisition of environmental knowledge. Nevertheless, Carrete et al. (2012) argue their findings imply that social institutions such as school where younger people are exposed to environmental knowledge play important roles in acquiring and shaping environmental knowledge, attitude and practices. Contrary to studies vouching for the link between age and ecological behaviour, Wiernik et al. (2012) established that consumer age was unrelated to environmental awareness and behaviour.

Education is considered to be positively associated with environmental concerns and behaviour. Educated consumers are assumed to have access to environmental information, have superior analytical abilities and moral judgement of the impact of their behaviour on the environment. On the contrary, people with little formal education are more likely to suffer impaired abilities for processing complex information and not motivated to make responsible decisions regarding their actions on the environment. Studies report inconsistent results concerning the relationship between consumer demographics and pro-environmental behaviour. Chan (2000) established that consumer age and education had little influence on environmental concern and pro-environmental behaviour. This finding is partially verified by Nittala (2014) who established that age had negative influence on environmental attitudes in India. On the other hand, Shen and Saijo (2008) showed that consumer age and education had positive influence on ecological concern in China.

Studies using gender to explain pro-environmental behaviour have reported inconsistent results, with majority suggesting that women tend to be more pro-environmental than their male counterparts. The first group of studies indicate that pro-environmental consumer attitudes and behaviour are more widespread among women than men (Zelezny et al., 2000). Eisenberg (2002) explains that unlike men, women are altruistic and designed to be interdependent and caring, hence their pro-environmental behaviour. Jain and Kaur (2006) established that women are inclined to care about the environment by buying green products. Kalantari et al. (2007) reported that concern for the environment was more prevalent among women than men in Iran. Similarly, Sherkat and Ellison (2007) obtained evidence in America showing that women were more pro-environmental than men. In addition, Lee (2009) found that women in Hong Kong and China had strong ecological attitudes and actual pro-environmental behaviours.

On the contrary, another group of studies (Blankenau, Snowden \& Langan, 2008) have demonstrated that pro-environmental behaviour is not gender dependent. The third collection of studies (Eisler, Eisler \& Yoshinda, 2003; Mostafa, 2007) has reported that men are more pro-environmental than women. Rather than gender based pro-environmental tagging, Hunter, Hatch and Johnson (2004) argue that both gender are pro-environmental, but with varying concentration based on gender driven roles. They aver that household oriented pro-environmental consumer behaviour is more established among women while men are more involved in community oriented environmental actions such as policy lobbying and protests.

Although theories of reasoned action and planned behaviour (Ajzen, 1991) predict human behaviour using attitude, studies pursuing the attitude-behaviour link have churned out contradictory results. Whereas some studies demonstrate significant link between attitude and pro-environmental behaviour, several studies have not found significant direct relationship. Bhuian and Sharma (2017) established that attitude was a good predictor of pro-environmental behaviour. Besides the direct link, their results indicate that the relationship between consumer attitude and pro-environmental behaviour was moderated by religiosity; the stronger the religious beliefs and faith in the supernatural, the higher chances of pro-environmental behaviour by individual consumers and groups in a society. Religion plays key role in framing people's beliefs and social norms. Therefore, religious beliefs lead to formation of consumer attitude towards the environment. On the contrary, Hughner (2007) presents results indicating that attitude was a poor predictor of pro-environmental consumer behaviour. Mostafa (2007) observed that previous studies report moderate to weak relationship between attitude and 
pro-environmental consumer behaviour. Nevertheless, Chen and Chai (2010) insist there is discrepancy between attitude and actual consumer behaviour.

Despite having positive attitude towards the environment, Dubey (2008) shows that consumers in Japan did not exhibit pro-environmental behaviours. Another paper (Frank, 2009) established that the purchase behaviour of consumers in China was incongruent to their environmental attitude. Similarly, evidence from the United Kingdom (Joshi \& Rahman, 2015) showed disconnect between positive attitude towards the environment and actual purchase behaviour. So far, empirical evidences above demonstrate that positive attitude towards the environment do not necessarily translate to pro-environmental consumer behaviour. Therefore, disconnect between what people think, believe and their actual behaviour suggests the possibility of other factors apart from awareness and attitude that explain actual behaviour. Sharma and Bansal (2013) argue that rational and emotional judgement by people about their actions to the environment is necessary, but not sufficient condition for pro-environmental behaviour.

The attitude-behaviour gap has been explained using situational factors surrounding the purchase decision. The attitude-behaviour-context (ABC) model introduced by Guagnano et al. (1995) explains that behaviour is a resultant of both attitude and contextual factors. Like the Schwart's norm activation theory (Sawitri et al., 2015), the attitude-behaviour-context model suggests that the relationship between attitude and behaviour is strengthened by supportive contextual factors. Contextual factors comprise economic circumstances, marketing mix elements, policy and legislative environment. LaMorte (2016) argues that pro-environmental behaviour is influenced by a broad range of contextual factors including consumer's income, fear of inaction, and threat to livelihoods, past experience with a product, time and effort necessary to access green products. Pro-environmental attitudes are influenced by situational factors. For instance, educated people become more aware of environmental issues and develop positive attitudes and concern for the environment (Diamantopoulos et al., 2003). Hence, education of people indirectly creates the motivation for environmental responsive behaviours. On the flipside, unfavourable situational conditions weaken the strength of the relationship between attitude and behaviour to the extent that people with strong positive attitude are not motivated to act pro-environmentally. Nonetheless, under favourable situational conditions, positive environmental attitudes translate to pro-environmental consumer behaviour.

External factors within consumer's decision making context have been identified as key influencers of pro-environmental behaviour. Personal disposable income is considered a trigger to environmental sensitivity. The argument linking income with environmental sensitivity is premised on the assumption that people with higher incomes can afford higher prices associated with pro-environmental products (Straughan \& Roberts, 1999). According to Moser (2015), high income individuals are more concerned about the environment, less sensitive to price and they often trade-off higher cost for environmental benefits. Nevertheless, other researchers observe that regardless of income levels, people can behave pro-environmentally for different reasons. Carrete et al. (2012) established that people with low earnings engage in pro-environmental behaviour to save money. In other words, income conditions behaviour of low income consumers in ways that make them recycle products, adopt efficient water and energy use, primarily to reduce the financial burden associated with acquisition and use of products. As a result, the environment benefits from unintended pro-environmental consumer behaviour by the low income market segment. Although Sharma and Bansal (2013) report that high income individuals are more informed about pro-environmental gains, they caution that the direct relationship between income and green consumption behaviour has not been supported by majority of the studies. Therefore, income, like other contextual factors generates attitude towards the environment that ultimately translates to actual behaviour through either intentional decisions or involuntary actions.

Socialization process in society has implications on consumer attributes and behaviour. Shamdasani et al. (1993) argue that pro-environmental consumers are open minded and more socially integrated in society. Social networks have been found to have greater influence on pro-environmental consumer behaviour (Muralidharan \& Xue, 2016). In light of the theory of reasoned action, social networks determine subjective norms which create an individual's perception of behaviour expected by important others (Mancha \& Yoder, 2015). Therefore, social networks that place importance on ecological behaviour emit pressure that forces consumers to conform by showing concern for the environment and eventually adopting pro-environmental behaviours. Sharma and Foropon (2019) established that consumers that demonstrate more concern for the environment unconditionally purchase green products. Whereas social network has been linked positively to pro-environmental consumer behaviour, actual behaviour depends on the honesty of people in the network and their degree of influence on others within the social network. The goal framing theory warns that norm-conforming behaviour is sensitive to violation of rules by few individuals within the social network. Selective conformance to norms by few dishonest 
people opens the door to moral hypocrisy allowing other individuals to twist interpretation of subjective norms to the point that they feel good by avoiding the cost of pro-environmental behaviour (Lindenberg \& Steg, 2007). When this happens, social network loses its power to positively generate pro-environmental behaviours.

An extrinsic factor closely related to social network is culture. Cultural factors are predicted to influence individual consumer's ethically responsible values and decisions (Vitell, 2003). Using the cultural dimensions by Hofstede (1997), Husted and Allen (2008) observed that collectivist societies prioritize common good for society and are most likely pro-environmental. Laroche et al. (2001) link pro-environmental behaviours to cultural inclination, arguing that individualistic societies care less about ecological issues. Conversely, collectivist societies are more conscious about the impact of their actions on the environment. Kim and Choi (2005) observed that collectivist societies tend to emphasize benefits to the group than individual gain. Consequently, they sacrifice individual interests to benefit community wellbeing. Considering that collectivists place higher value on stability and predictability, they are motivated to protect the environment during and after consumption to avoid disrupting the ecological balance.

Thorgerson and Olander (2002) find in their review of literature that environmentally friendly behaviour is related to certain cultural values. They argue that reasons for changes in values can be traced to three basic causes comprising differences between generations, changing conditions over an individual's life cycle, and periodic influences such as major personal or society-wide events. Follows and Jobber (2000) suggest that cultural values have indirect influence on behaviour through attitude. Cultural values such as altruism, universalism and benevolence have been found to be positively related to consumer attitude and behaviour (Doran, 2009). In a panel study of Danish consumers, Curran and Sherbinin (2004) found that values such as universalism which mean strong beliefs in protecting the environment, unity with nature, social justice, and equality can strongly affect the propensity of consumers to avail themselves new opportunities to engage in environmentally sustainable consumption activities. Thorgerson and Olander (2002) argue that over the longer term, engagement in such activities even if symbolic can result in shifts in values which influence other areas of consumption behaviour towards enhanced sustainability. Cerjak et al. (2010) established that health and safety values were associated with pro-environmental behaviour, suggesting that people engage in pro-environmental behaviours for personal benefits and safety reasons.

Cultural values are instilled into people by social agents and social institutions such as religion, family and schools. Religion provides value system that determines people's social identity and attitude (Rice, 2006). Researchers argue that religiosity influences the formation of a variety of values, attitudes and behaviours in societies where people hold strong religious beliefs (Bhuian \& Sharma, 2017). The influence of religion on consumer attitude and behaviour appear to cut across religious beliefs and denominations. In a study of Muslims in Egypt, Rice (2006) established that religion had positive influence on pro-environmental behaviour. Moreover, Felix and Braunsberger (2016) found that religiosity moderated the relationship between attitude and behaviour of consumers in Mexico.

\section{Barriers to Pro-Environmental Consumer Behaviour}

The possibility for consumers to develop pro-environmental attitude and behaviour is impeded by a host of extrinsic factors including marketing mix related, situational issues and consumer socio-economic circumstances. The impeders are interrelated and work through complex interactions during consumer decision making process that result to unintentional harm to the environment. Connell (2010) argues that inadequate financial resources among consumers exacerbate perceptions of price associated with green products hence, erect barriers to pro-environmental consumer behaviour. Consumers with low personal disposable income may tend to shy away from purchasing high priced green products to save money. Nonetheless, the purchase of green products is not only subject to personal income, but more importantly attached to consumer's purchase objective. A high income earner with the objective of saving money during an exchange process is likely to consider low priced products in the market. Whereas high income earners may be aware about green products and their benefits, personal economic gain through cost cuts may overshadow overall befits to the ecosystem. Alternatively, personality of the consumer (Gatersleben et al., 2012) may nudge him/her to buy expensive, but environmentally unfriendly products. For example, high income consumers may prefer self expressive fuel guzzler cars as compared to solar powered cars or fuel efficient smaller car models without care to carbon emission consequences.

Negative attitude towards pro-environmental products has been linked to their slow uptake in the market. McKenzie-Mohr (2000) argues that consumers view sustainable consumption actions as requiring substantial effort, time consuming and difficult to undertake. When consumers develop negative attitude towards performing behaviour, it becomes difficult to voluntarily change their behaviour hence a barrier to pro-environmental 
consumption. Extant literature on consumer behaviour links cultural makeup of a society to attitude towards green products. Trianids (1993) points out that individualism society is less motivated to engage in pro-environmental consumer behaviour than collectivist culture. Similarly, Laroche et al. (2001) contend that the drive to engage in environmental friendly behaviours is stronger in collectivist culture as compared to individualist society. Individualist societies tend to prefer private economic gains to collective societal wellbeing. Therefore, in such societies, people tend to consume products that deliver greatest perceived value irrespective of environmental consequences. As such, consumers are likely to develop negative attitude towards pro-environmental behaviours. Change of attitude may require incentives from the marketing mix elements and the environment within which the consumer operates. For example, the incentives may include developing user friendly products, more perceived benefits to the consumer, providing convenient access to green products and green consumption supportive policies. Moreover, availability of waste disposal facilities within residential places may increase the chances of safe disposal of household wastes without posing danger to the environment.

Gleim et al. (2013) claimed that high price is a barrier to ecological consumption. However, it is not only actual high price, but also the perception of price that negatively affect pro-environmental consumer behaviour. Narula and Desore (2016) assert that perceived high price of green products make it difficult for consumers to buy pro-environmental products. High price associated with green products outweigh ethical considerations and increase the gap between attitude and actual behaviour (Joshi \& Rahman, 2015). In addition, perceived financial risk has been found to lower the intention to purchase green products (Abu-Elsamen et al., 2018).

Apart from the lack of economic access to green products, lack of environmental knowledge and difficulty in accessing ecological products are significant hurdles to pro-environmental consumption behaviour (Young et al., 2010). Davies et al. (1995) observed that unavailability of environment friendly products in the shopping outlets is a barrier to pro-environmental consumer behaviour. According to Vermeir and Verbeke (2004), unavailability of green products discourages consumers from engaging in environmentally directed behaviours. Consumers are reluctant to spend a lot of time and effort searching for green products and prefer products that can be conveniently accessed (Joshi \& Rahman, 2015). Therefore, inefficiencies in distribution network for green products dilute the effect of product awareness and blocks exchange process associated with ecological products. However, Small and Dender (2007) controversially argue that availability of environmentally friendly technologies and resources lead to negative spill-over effects. In support of this view, Catlin and Wand (2013) presented empirical evidence showing that consumers used more resources for which they knew they are recyclable. In other words, people tend to be more conservative with the use of non-renewable and costly resources than renewable or recyclable resources. Nevertheless, this behaviour is not necessarily universal and may vary depending on product category, recycling costs, recycling effort, and nature of society.

Lack of trust and perceived green product performance risks pose a threat to pro-environmental consumer behaviours. Although Ranbar and Wahid (2011) propose eco-labelling as predictor of green product purchase, pro-environmental consumer behaviour depends on the level of trust people have on green product claims and labelling. Tung et al. (2012) established that lack of trust and confidence were major barriers to pro-environmental consumer behaviour. Nittala (2014) established that consumers do not trust green product information and were sceptical towards labelling and certification procedures of green products. Lack of trust may be due to limited knowledge about the environment. Environmental knowledge relates to the amount of information people have about the environment. Therefore, limited environmental knowledge negatively affects people's beliefs about green product claims. As a result, limited information about the environment and lack of previous experience with ecological products reduce consumer trust on green products. Even though consumers may develop trust on green products, deceptive marketing comprising misleading advertising and packaging (Kaufman et al., 2012) may destroy that trust when consumers discover the unethical tricks used by marketers and more so when products fail to meet consumer's expectations. Hence, unethical marketing is a barrier to pro-environmental consumer behaviour.

\section{Conclusion}

Human behaviour occurs as a result of complex interrelationships among factors within the consumer and the environment. Pro-environmental consumer behaviour is a decision outcome formed by cognitive and emotional processes that are influenced by contextual factors. Attitude is at the centre stage of pro-environmental consumer behaviour. The current study challenges the notion that environmental knowledge moderates the relationship between attitude and behaviour. Instead, it argues that knowledge is acquired over time and there are two types of knowledge namely: pre-attitude knowledge and post-attitude knowledge. Pre-attitude knowledge leads to initial attitude formation while post-attitude knowledge changes attitude. Hence, the moderation effect could result from post-attitude knowledge. Theories of behaviour change use attitude to explain pro-environmental 
consumer behaviour. The norm activation theory argues that awareness of consequences of consumption behaviour and attribution of responsibility for behavioural outcomes are basic conditions for pro-environmental behaviour. However, attribution of responsibility for the outcomes is an attitude dependent process. Despite awareness of consequences of consumption related behaviours, people may not act in an environment friendly manner if they have negative attitude and more so when they feel others are responsible for sustainability of the environment. Therefore, the norm activation theory does not explain denial of responsibility for the consequences of consumption behaviour.

Empirical studies have established a gap between attitude and behaviour. Although people may develop pro-environmental attitude, the lack of capacity to act may frustrate happening of actual behaviour. Barriers to pro-environmental consumer behaviour may include high price for green products, unavailability of eco-friendly products and lack of trust. Lack of trust and relative high price of green products are the major impediments to pro-environmental consumer behaviour. Literature profiles pro-environmental consumer as young, well educated and high income female. However, the role of gender remains controversial as some strand of studies suggests that both gender act in environmental sustainable manner but differ on roles they play. In addition, studies testing the influence of income on pro-environmental consumer behaviour have yielded inconsistent results indicating that purchase behaviour vary on the objective of the consumer. Therefore, the current study concludes that gender and income are weak predictors of pro-environmental consumer behaviour.

The current study concludes that awareness and knowledge about environmental issues create attitude which in turn leads to concern for the environment. Once concern is developed, people attribute responsibility for consequences of their behaviour to the extent of intensity of concern. Consumers with greater concern are most likely to assume higher responsibility for behavioural outcomes. Finally, actual behaviour takes place as anticipatory measure for possible negative consequences on the environment. I conclude that attitude without supportive contextual factors, is feeble and do not lead to pro-environmental consumer behaviour. On the other hand, the mere presence of favourable contextual factors in the face of negative attitude has little force to cause green consumption behaviours. Therefore, pro-environmental consumer behaviour is a product of positive attitude and favourable contextual factors. Hence, the creation of pro-environmental consumer behaviours calls for actions directed at attitude change management and ensuring there are supportive contextual factors.

\section{References}

Abu-Elsamen, A. A., Akrooush, N. M., Asfour, A. N., \& Jabali, A. K. (2018). Understanding contextual factors affecting the adoption of energy-efficient household products in Jordan. Sustainability Accounting, Management and Policy Journal, 10(2), 314-332. https://doi.org/10.1108/SAMPJ-05-2018-0144

Ajzen, I. (1991). The theory of planned behavior. Organizational Behaviour and Human Decision Processes, 50, $179-211$.

Ajzen, I. (1988). Attitudes, Personality and Behaviour. Chicago: Dorsey

Barr, S. (2007). Factors influencing environmental attitudes and behaviours; A UK case study of household waste management. Environment and Behaviour, 39(4), 435-473. https://doi.org/10.1177/0013916505283421

Bhuian, S., \& Sharma, K. S. (2017). Predicting consumer pro-environmental behavioural intention; the moderating role of religiosity. Review of International Barriers and Strategy, 27(3), 352-368. https://doi.org/10.1108/RIBS-03-2017-0022

Blankenau, J., Snowden, M., \& Langan, M. (2008). Understanding environmentalism in a red, agriculture state: The most impact of political party identification and place of residence. Sociological Spectrum, 28(1), 55-80, https://doi.org/10.1080/02732170701675201

Bray, J., Johns, N., \& Kilburn, D. (2011). An exploratory study into factors impeding ethical consumption", Journal of Business, 98(4), 597-608, https://doi.org/10.1007/s10551-010-0640-9

Buttel, F. H., \& Taylor, P. J. (1992). Environmental sociology and global environmental change: A critical assessment. Society and Natural Resources, 5(3), 211-230.

Carrington, M. J., Neville, B. A., \& Whitwell, G. J. (2010). Why ethical consumers don't walk the talk: Towards a framework for understanding the gap between the ethical purchase intentions and actual buying behaviour of ethically minded consumers. Journal of Business Ethics, 97(1), 138-158, https://doi.org/10.1007/s10551-010-0501-6 
Carrete, L., Castano, R., Felix, R., Centeno, E., \& Gonzaloz, E. (2012). "Green consumer behaviour in an emerging economy: confusion, credibility and compatibility. Journal of Consumer Marketing, 29(7), 740-481. https://doi.org/10.1108/07363761211274983

Castaneda, G. M., Martinez, P. C., Marte, R., \& Roxas, B. (2015). Explaining the environmentally sustainable consumer behaviour: a social capital perspective. Social Responsibility Journal, 11(4), 658-676. https://doi.org/10.1108/SRJ-02-2014-0019

Catlin, J. R., \& Wang, Y. (2013). Recycling gone bad: When the option to recycle increases resource consumption. Journal of Consumer Psychology, 23(1), 122-27, https://doi.org/10.1016/j.jcps.2012.04.001

Cerjak, M., Mesic, Z., Kopic, M., Kovacic, D., \& Markovina, J. (2010). What motivates consumers to buy organic food: Comparison of Croatia, Bosnia Herzegovina, and Slovenia. Journal of Food Products Marketing, 16(3), 278-292. https://doi.org/10.1080/10454446.2010.484745

Chan, K. (2000). Market segmentation of green consumers in Hong Kong. Journal of International Consumer Marketing, 12(2), 7-24. https://doi.org/10.1300/j046v12n02_02

Chan, A., Wong, S., \& Leung, P. (2008). Applying ethical concepts to the study of green consumer behaviour: An analysis of Chinese consumer's intentions to bring their own shopping bags. Journal of Business Ethics, 79, 469-481. https://doi.org/10.1007/s10551-007-9410-8

Chen, T. B., \& Chai, L. T. (2010). Attitude towards the environment and green products: Consumers' perspective. Management Science and Engineering, 4(2), 27-39

Connell, K. Y. H. (2010). Internal and external barriers to eco-conscious apparel acquisition. International Journal of Consumer Studies, 34(3), 279-286. https://doi.org/10.1111/j.1470-6431.2010.00865.x

Corral-Verdugo, V. (2001). Comportamiento Proambiental. Una Introduction al Estudio de las Conductas Protectoras del Ambiente. RESMA, Santa Cruz de Tenerife

Cropanzano, R., \& Mitchell, S. M. (2005). Social exchange theory: An interdisciplinary review. Journal of Management, 31(6), 874-900. https://doi.org/10.1177/0149206305279602

Curran, R. S., \& Sherbinin, A. (2004). Completing the Picture: The Challenges of Bringing Consumption into the Population Environment Equation. Population and Environment, 26(2), 107-131.

Davies, A., Titterington, A. J., \& Cochrane, C. (1995). Who buys organic food? A profile of the purchasers of organic food in Northern Ireland. British Food Journal, 97(10), 17-23.

Davis, J. J. (1992). Ethics and Environmental Marketing. Journal of Business Ethics, 11(2), 81-87. https://doi.org/10.1007/BF00872314

Dean, M., Raats, M. M., \& Shepherd, R. (2008). Moral concerns and consumer choice of fresh and processed organic foods. Journal of Applied Social Psychology, 38(8), 2088-2107. https://doi.org/10.1111/j.1559-1816.2008.00382.x

Diamantopoulos, A., Schlegelmilch, B. B., Sinkovics, R. R., \& Bohlen, G. M. (2003). Can socio-demographics still play a role in profiling green consumers? A review of the evidence and an empirical investigation. Journal of Business Research, 56(6), 465-480. https://doi.org/10.1016/S0148-2963(01)00241-7

Doran, C. J. (2009). The role of personal values in fair trade consumption. Journal of Business Ethics, 84(4), 549-563. https://doi.org/10.1007/s10551-008-9724-1

Dubey, P. (2008). Recycling businesses: cases of strategic choice of green marketing in Japan. IMB Management Review, 20(3), 263-278.

Eisenberg, N. (2002). Empathy related emotional responses, altruism and their socialization. In R.J. Davidson \& A. Harrington (Eds.), Visions of compassion: Western Scientists and Tibetan Buddists examine human nature (pp. 131-164). https://doi.org/10.1093/acprof:oso/9780195130430.003.0007

Eisler, A. D., Eisler, H., \& Yoshinda, M. (2003). Perception of human ecology: Cross-cultural and gender comparisons", Journal of Environmental Psychology, 23(1), 89-101. https://doi.org/10.1016/S0272-4944(02)00083-X

Eze, U. C., \& Ndubisi, N. O. (2013). Green buyer behaviour: evidence from Asia consumers. Journal of Asian and African Studies, 48(4), 413-426. https://doi.org/10.1177/0021909613493602 
Farrukh, M., Alzubi, Y., Shahzad, I. A., Waheed, A., \& Kanwal, N. (2018). Entrepreneurial intentions: the role of personality traits in perspective of theory of planned behaviour. Asia Pacific Journal of Innovation and Entrepreneurship, 12(3), 399-414.

Felix, R., \& Braunsberger, K. (2016). I believe therefore I care: the relationship between religiosity, environmental attitudes and green product purchase in Mexico. International Marketing Review, 33(1), 137-155. https://doi.org/10.1108/imr-07-2014-0216

Fishbein, M., \& Ajzen, I. (1975). Belief, Attitude, Intention and Behaviour: An Introduction to Theory and Research. Reading, MA: Addison-Wesley

Frank, J. (2009). Green still appeals to cash strapped consumers. Marketing Management, 18(2), 3-4.

Fujii, S. (2006). Environmental concern, attitude toward frugality, and ease of behaviour as determinants of pro-environmental behaviour intentions. Journal of Environmental Psychology, 26, 262-268. https://doi.org/10.1016/j.jenvp.2006.09.003

Follows, B. S., \& Jobber, D. (2000). Environmentally responsible purchase behaviour: a test of consumer model. European Journal of Marketing, 34(5/6), 723-746. https://doi.org/10.1108/03090560010322009

Gatersleben, B., Murtagh, N., \& Abrahamse, W. (2012). Values, identity and pro-environmental behaviour. Contemporary Social Sciences, 9(4), 374-392. https://doi.org/10.1080/21582041.2012.682086

Gifford, R., \& Nilsson, A. (2014). Personal and social factors that influence pro-environmental concern and behaviour: A review. International Journal of Psychology. https://doi.org/10.1002/ijop.12034

Gilg, A., Barr, S., \& Taylor, P. J. (1992). Environmental sociology and global environmental change: a critical assessment. Society and Natural Resources, 5(3), 211-230, https://doi.org/10.1080/08941929209380788

Gino, F., \& Pierce, L. (2009). Dishonesty in the name of equity. Psychological Science, 20, 1153-1160. https://doi.org/10.1111/j.1467-9280.2009.02421.x

Gleim, M. R., Smith, J. S., Andrews, D., \& Cronin, J. J. Jr. (2013). Against the green: A multi-method examination of the barriers to green consumption. Journal of Retailing, 89(1), 44-61. https://doi.org/10.1016/j.jretai.2012.10.001

Guagnano, G. A., Stern, P. C., \& Dietz, T. (1995). Influences on attitude-behaviour relationships, a natural experiment with curbside recycling. Environment and Behaviour, 27(5), 699-718. https://doi.org/10.1177/0013916595275005

Hofstede, G. (1997). Cultures and Organizations: Software of the Mind. NY: McGraw Hill

Honkanen, P., Verplanken, B., \& Olsen, S. O. (2006). Ethical values and motives driving organic food choice", Journal of Consumer Behaviour, 5, 420-430. https://doi.org/10.1002/cb.190

Horne, C. (2001). Sociological perspectives on the emergence of norms. In Michael Hechter and Karl-Dieter Opp (Eds.), Social Norms (pp. 3-34). New York: Russell Sage

Hughner, R. S., McDonagh, P., Prothero, A., Shultz, C. J., \& Stanton, J. (2007). Who are organic food consumers? A compilation and review of why people purchase organic food. Journal of Consumer Behaviour, 6(2/3), 94-110. https://doi.org/10.1002/cb.210

Husted, B. W., \& Allen, D. B. (2008). Toward a model of cross-cultural business ethics: The impact of individualism and collectivism on the ethical decision-making process. Journal of Business Ethics, 82, 293-305. https://doi.org/10.1007/s10551-008-9888-8

Hunter, L. M., Hatch, A., \& Johnson, A. (2004). Cross-national gender variation in environmental behaviours. Social Science Quarterly, 85(3), 677-694. https://doi.org/10.1111/j.0038-4941.2004.00239.x

Jain, S. K., \& Kaur, G. (2006). Role of socio-demographics in segmenting and profiling green consumers. Journal of International Consumer Marketing, 18(3), 107-146. https://doi.org/10.1300/J046v18n03_06

Joshi, Y., \& Rahman, Z. (2015). Factors affecting green purchase behaviour and future directions. International Strategic Management Review, 3, 128-143. https://doi.org/10.1016/j.ism.2015.04.001

Kalantari, F., Fami, H. S., Asadi, A., \& Mohammadi, H. M. (2007). Investigating factors affecting environmental behaviour of urban residents: a case study in Tehran city-Iran. American Journal of Environmental Sciences, 3(2), 67-74. 
Kaufman, R. H., Panni, M. F. A. K., \& Orphanidou, Y. (2012). Factors affecting consumers' green purchasing behaviour: An integrated conceptual framework. Amfiteatru Economic, 14(31), 50-69.

Kim, Y., \& Choi, S. M. (2005). Antecedents of green purchase behaviour: An examination of collectivism, environmental concern, and PCE. Advances in Consumer Research, 32, 592-599.

Kim, Y. (2011). Understanding green purchase: The influence of collectivism, personal values and environmental attitudes, and the moderating effect of perceived consumer effectiveness. Seoul Journal of Business, 17(1), 65-92. https://doi.org/10.35152/snusjb.2011.17.1.003

LaMorte, W. W. (2016). Theory of Planned Behaviour, Boston University School of Public Health. Retrieved from

http://sphweb.bumc.bu.edu/otlt/MPH-Modules/SB/BehaviouralChangeTheories/BehaviouralChangeTheorie s3.html

Laroche, M., Bergeron, J., \& Barbaro-Forleo, G. (2001). Targeting consumers who are willing to pay more for environmentally friendly products. The Journal of Consumer Marketing, 18(6), 503-520.

Lee, K. (2009). Gender differences in Hong Kong adolescent consumers' green purchasing behaviour. Journal of Consumer Marketing, 26(2), 87-96. https://doi.org/10.1108

Lindenberg, S. M., \& Steg, L. (2013). Goal-framing theory and norm-guided environmental behaviour. In H.C.M. van Trijp (Ed.), Encouraging Sustainable Behaviour: Psychology and the Environment (pp. 37-54). New York: Psychology Press.

Lindenberg, S. (2009). Values: What do they do for behaviour? In Mohamed Cherkaoui and Peter Hamilton (Eds.), Boudon: A Life in Sociology (Vol. 3, pp. 59-89). Oxford: Bardwell Press.

Lindenberg, S., \& Steg, L. (2007). Normative, gain and hedonic goal-frames guiding environmental behaviour. Journal of Social Issues, 65(1), 117-137. https://doi.org/10.1111/j.1540-4560.2007.00499.x

Lu, L. C., Chang, H. H., \& Chang, A. (2015). Consumer personality and green buying intention: The moderating role of consumer ethical beliefs. Journal of Business Ethics, 127(1), 205-219. https://doi.org/10.1007/s10551-013-2024-4

Mainieri, T., Barnett, E. G., Valdero, T. R., Unipan. J. B., \&Oskamp, S. (1997). Green buying: The influence of environmental concern on consumer behaviour. The Journal of Social Psychology, 137(2), 189-204, https://doi.org/10.1080/00224549709595430

Malik, I. M., Mir, N. F., Hussain, S., Hyder, S., Anwar, A., Khan, U. Z., Nariab, N., Shah, A. F. S., \& Waseem, M. (2019). Contradictory results on environmental concern while re-writing green purchase awareness and behaviour. Asia Pacific Journal of Innovation and Entrepreneurship, 13(1), 17-28. https://doi.org/10.1108/APJIE-11-2018-0061

Mancha, M. R., \& Yoder, Y. C. (2015). Cultural antecedents of green behavioural intent: An environmental theory of planned behaviour. Journal of Environmental Psychology, 43, 145-154. https://doi.org/10.1016/j.jenvp.2015.06.005

McKenzie-Mohr, D. (2000). New ways to promote pro-environmental behaviour: Promoting sustainable behaviour: An introduction to community-based social marketing. Journal of Social Issues, 56(3), 543-54. https://doi.org/10.1111/0022-4537.00183

Michaud, C., \& Llerena, D. (2011). Green consumer behaviour: an experimental analysis of willingness to pay for remanufactured products. Business Strategy and Environment, 20, 408-420. https://doi.org/10.1002/bse.703

Mohr, L. A., Webb, D. J., \& Harris, K. E. (2001). Do consumers expect companies to be socially responsible? The impact of corporate social responsibility on buying behaviour. Journal of Consumer Affairs, 35(1), 45-72. https://doi.org/10.1111/j.1745-6606.2001.tb00102.x

Moser, K. A. (2015). Thinking green, buying green? Drivers of pro-environmental purchasing behaviour. Journal of Consumer Marketing, 32(3), 167-175. https://doi.org/10.1108/JCM-10-2014-1179

Mostafa, M. M. (2007). Gender differences in Egyptian consumers' green purchase behaviour: The effects of environmental knowledge, concern and attitude. International Journal of Consumer Studies, 31, 220-229. https://doi.org/10.1111/j.1470-6431.2006.00523.x 
Muralidharan, S., \& Xue, F. (2016). Personal networks as a precursor to a green future: a study of 'green' consumer socialization among young millennial from India and China. Young Consumers, 17(3), $226-242$. https://doi.org/10.1108/YC-03-2016-00586

Narula, A. S., \& Desore, A. (2016). Framing green consumer behaviour research: opportunities and challenges. Social Responsibility Journal, 12(1), 1-22. https://doi.org/10.1108/SRJ-08-2014-0112

Nittala, R. (2014). Green consumer behaviour of the educated segment in India. Journal of International Consumer Marketing, 26(2), 138-152. https://doi.org/10.1080/08961530.2014.878205

Olney, T. J., \& Bryce, W. (1991). Consumer Responses to Environmentally Based Product Claims. Advances in Consumer Research, 18, 693-696.

Oom Do Valle, P. E., Rebelo, E. R., \& Menezes, J. (2005). Combining behavioural theories to predict recycling involvement. Environment and Behaviour, 37, 364-396

Papaoikonomou, E., Ryan, G., \& Valverde, M. (2011). Mapping ethical consumer behaviour: Integrating the empirical research and identifying future directions. Ethics and Behaviour, 21(3), 197-221. https://doi.org/10.1080/10508422.2011.570165

Pieters, R. G. M. (1991). Changing Garbage Disposal Patterns of Consumers: Motivation, Ability and Performance. Journal of Public Policy and Marketing, 10(2), 59-76.

Ranbar, E., \& Wahid, N. A. (2011). Investigation of green marketing tools' effect on consumers' purchase hebahiour. Business Strategy Series, 12(2), 73-83. https://doi.org/10.1108/17515631111114877

Ramayah, T., Lee, J. W. C., \& Mohamad, O. (2010). Green product purchase intention: Some insights from a developing country. Resources, Conservation and Recycling, 54(12), 1419-1427. https://doi.org/10.1016/j.resconrec.2010.06.007

Rice, G. (2006). Pro-environmental behaviour in Egypt: is there a role for Islamic environmental ethics? Journal of Business Ethics, 65(4), 373-390. https://doi.org/10.1007/s10551-006-0010-9

Sanne, C. (2002). Willing consumers or locked-in? Policies for a sustainable consumption. Ecological Economics, 42, 273-287.

Santos, G. (2008). The London experience. In E. Verhoef, B. Van Wee, L. Steg, \& M. Bliemer (Eds.), Pricing in road transport: Multi-disciplinary perspective (pp. 273-292). Cheltenham: Edgar Elgar.

Schwartz, S. H. (1977). Normative influences on altruism. In, L. Berkowitz (Ed.), Advances in experimental social psychology, 10, 221-279. New York: Academic Press. https://doi.org/10.1016/S0065-2601(08)60358-5

Shamdasani, P., Chon-Lin, G., \& Richmond, D. (1993). Exploring green consumers in an oriental culture: the role of personal and marketing mix factors. Advances in Consumer Research, 20(1), 488-493.

Sharma, K., \& Bansal, M. (2013). Environmental consciousness, its antecedents and behavioural outcomes. Journal of Indian Business Research, 5(3), 198-214, https://doi.org/10.1108/JIBR-10-2012-0080

Sharma, A., \& Foropon, C. (2019). Green product attributes and green purchase behaviour: A theory of planned behaviour perspective with implications for circular economy. Management Decision, 57(4), 1018-1042. https://doi.org/10.1108/MD-10-2018-1092

Shen, J., \& Saijo, T. (2008). Re-examining the relations between socio-demographic characteristics and individual environmental concern: evidence from Shanghai data. Journal of Environmental Psychology, 28(1), 42-50. https://doi.org/10.1016/j.jenvp.2007.10.003

Sherkat, D. E., \& Ellison, C. G. (2007). Structuring the religion-environment connection: Identifying religious influences on environmental concern and activism. Journal of the Scientific Study of Religion, 46(1), 71-85.

Small, K. A., \& Dender, V. K. (2007). Fuel efficiency and motor vehicle travel: The declining rebound effect. The Energy Journal, 28(1), 25-51.

Spangenberg, J., \& Lorek, S. (2002). Environmentally sustainable household consumption: From aggregate environmental pressures to priority fields of action. Ecological Economics, 43, 127-140. https://doi.org/10.1016/S0921-8009(02)00212-4

Steg, L., \& Vlek, C. (2009). Encouraging pro-environmental behaviour: An integrative review and research agenda. Journal of Environmental Psychology, 29, 309-317. https://doi.org/10.1016/j.jenvp.2008.10.004 
Straughan, R. D., \& Roberts, J. A. (1999). Environmental segmentation alternatives: a look at green consumer behaviour in the new millennium. Journal of Consumer Marketing, 16(6), 558-575. https://doi.org/10.1108/07363769910297506

Tan, B. C. (2011). The role of perceived consumer effectiveness on value-attitude-behaviour model in green buying behaviour context. Australian Journal of Basic and Applied Sciences, 5(12), 1766-1771.

Thorgerson, J., \& Olander, F. (2002). Human values and the emergence of a sustainable consumption pattern: A panel study. Journal of Economic Psychology, 23, 605-630. https://doi.org/10.1016/S0167-4870(02)00120-4

Thogersen, J. (2005). How many consumer policies empower consumers for sustainable lifestyles? Journal of Consumer Policy, 28, 143-178. https://doi.org/10.1007/s10603-005-2982-8

Trafimow, D. (2009). The theory of reasoned action: A case study of falsification in psychology. Theory \& Psychology, 19(4), 501-518. https://doi.org/10.1177/0959354309336319

Tremblay, K. R., \& Dunlap, R. E. (1978). Rural-urban residence and concern with environmental quality: a replication and extension. Rural Sociology, 43(3), 474-491.

Trianids, H. C. (1993). Collectivism and individualism as cultural syndromes. Cross-cultural Research, 27(3), 155-180. https://doi.org/10.1177/106939719302700301

Tung, S. J., Shih, C. C., Wei, S., \& Chen, Y. H. (2012). Attitudinal inconsistency towards organic food in relation to purchasing intention and behaviour: An illustration of Taiwan consumers. British Food Journal, 114(7), 997-1015.

Vermeir, I., \& Verbeke, W. (2004). Sustainable Food Consumption: Exploring the Consumer Attitude-behaviour Gap. Working Paper, 24. https://doi.org/ 10.1007/s10806-005-5485-3

Vitell, S. J. (2008). Consumer ethics research: Review, synthesis and suggestions for the future. Journal of Business Ethics, 43(1/2), 33-47. https://doi.org/ 10.1023/A:1022907014295

Wang, P., Liu, Q., \& Qi, Y. (2014). Factors influencing sustainable consumption behaviours: a survey of the rural residents in China. Journal of Cleaner Production, 63, 152-165. https://doi.org/10.1016/j.jclepro.2013.05.007

Wiernik, M. B., Ones, S. D., \& Dilchert, S. (2012). Age and environmental sustainability: A meta-analysis. Journal of Managerial Psychology, 28(7/8), 826-856. https://doi.org/10.1108/JMP-07-2013-0221

Witkowski, H. T. (2005). Anti-global Challenges to Marketing in Developing Countries: Exploring the Ideological Divide. Journal of Public Policy and Marketing, 24(1), 7-23.

Young, W., Hwang, K., McDonald, S., \& Oates, C. J. (2010). Sustainable consumption: Green consumer behaviour when purchasing products. Sustainable Development, 18(1), 20-31. https://doi.org/10.1002/sd.394

Zelezny, L. C., Chua, P. P., \& Aldrich, C. (2000). New ways of thinking about environmentalism: Elaborating on gender differences in environmentalism. Journal of Social Issues, 56, 443-457.

Zhao, H., Gao, Q., Wu, Y., Wang, Y., \& Zhu, X. (2014). What affects green consumer behaviour in China? A case study from Qingdao. Journal of Cleaner Production, 63, 145-151. https://doi.org/10.1016/j.jclepro.2013.05.021

\section{Copyrights}

Copyright for this article is retained by the author(s), with first publication rights granted to the journal.

This is an open-access article distributed under the terms and conditions of the Creative Commons Attribution license (http://creativecommons.org/licenses/by/4.0/). 